\title{
Histopathological features of papillary thyroid carcinomas detected during four screening examinations of a Ukrainian-American cohort
}

\author{
Tetiana I Bogdanova ${ }^{1}$, Liudmyla Yu Zurnadzhy ${ }^{1}$, Yuri E Nikiforov ${ }^{2}$, Rebecca J Leeman-Neill ${ }^{2}$, \\ Mykola D Tronko ${ }^{3}$, Stephen Chanock ${ }^{4}$, Kiyohiko Mabuchi ${ }^{4}$, llya A Likhtarov ${ }^{5}$, Leonila M Kovgan ${ }^{6}$, \\ Vladimir Drozdovitch ${ }^{4}$, Mark P Little ${ }^{4}$, Maureen Hatch ${ }^{4}$, Lydia B Zablotska7, Viktor M Shpak ${ }^{8}$, \\ Robert J McConnell ${ }^{9,10}$ and Alina $V$ Brenner ${ }^{\star}, 4$
}

${ }^{1}$ Laboratory of Morphology of Endocrine System, State Institution 'V.P. Komisarenko Institute of Endocrinology and Metabolism of Academy of Medical Sciences of Ukraine', Vishegorodskaya Street 69, Kyiv 254114, Ukraine; ${ }^{2}$ Department of Pathology, University of Pittsburgh School of Medicine, 3477 Euler Way, Pittsburgh, PA 15213, USA; ${ }^{3}$ Department of Fundamental and Applied Problems of Endocrinology, State Institution 'V.P. Komisarenko Institute of Endocrinology and Metabolism of Academy of Medical Sciences of Ukraine', Vishegorodskaya Street 69, Kyiv 254114, Ukraine; ${ }^{4}$ Radiation Epidemiology Branch, Division of Cancer Epidemiology and Genetics, National Cancer Institute, NIH, 9609 Medical Center Drive, MSC 9778, Bethesda, MD 20892-9778, USA; ${ }^{5}$ Department of Dosimetry and Radiation Protection, State Institution 'National Research Center for Radiation Medicine of Academy of Medical Sciences of Ukraine', Melnikova Street 53, Kyiv 04050, Ukraine; ' Laboratory of Radiation Protection, State Institution 'National Research Centre for Radiation Medicine of Academy of Medical Sciences of Ukraine', Melnikova Street 53, Kyiv 04050, Ukraine; ${ }^{7}$ Department of Epidemiology and Biostatistics, University of California San Francisco, 3333 California Street, San Francisco, CA 94118-1944, USA; ${ }^{8}$ Department of Medical Consequences of the Chernobyl accident and International Cooperation, State Institution 'V.P. Komisarenko Institute of Endocrinology and Metabolism of Academy of Medical Sciences of Ukraine', Vishegorodskaya Street 69, Kyiv 254114, Ukraine; ${ }^{9}$ The Thyroid Center, Columbia University, 161 Fort Washington Avenue, New York, NY, 10032, USA and ${ }^{10}$ Department of Medicine, College of Physicians and Surgeons, Columbia University, New York, NY, USA

Background: There are limited data on the histopathology of papillary thyroid carcinomas (PTCs) diagnosed in irradiated populations. We evaluated the associations between iodine-131 dose and the histopathological characteristics of post-Chernobyl PTCs, the changes in these characteristics over time, and their associations with selected somatic mutations.

\footnotetext{
Methods: This study included 115 PTCs diagnosed in a Ukrainian-American cohort $(n=13243)$ during prescreening and four successive thyroid screenings. Of these PTCs, 65 were subjected to somatic mutation profiling. All individuals were $<18$ years at the time of the Chernobyl accident and had direct thyroid radioactivity measurements. Statistical analyses included multivariate linear and logistic regression.
}

Results: We identified a borderline significant linear-quadratic association ( $P=0.063)$ between iodine-131 dose and overall tumour invasiveness (presence of extrathyroidal extension, lymphatic/vascular invasion, and regional or distant metastases). Irrespective of dose, tumours with chromosomal rearrangements were more likely to have lymphatic/vascular invasion than tumours without chromosomal rearrangements $(P=0.020)$ or tumours with BRAF or RAS point mutations $(P=0.008)$. Controlling for age, there were significant time trends in decreasing tumour size $(P<0.001)$, the extent of lymphatic/vascular invasion $(P=0.005)$, and overall invasiveness $(P=0.026)$.

Conclusions: We determined that the invasive properties of PTCs that develop in iodine-131-exposed children may be associated with radiation dose. In addition, based on a subset of cases, tumours with chromosomal rearrangements appear to have a more invasive phenotype. The increase in small, less invasive PTCs over time is a consequence of repeated screening examinations.

*Correspondence: Dr AV Brenner; E-mail: brennera@mail.nih.gov

Received 13 March 2015; revised 3 September 2015; accepted 27 September 2015; published online 3 December 2015

(c) 2015 Cancer Research UK. All rights reserved 0007 - 0920/15 
The increased risk of thyroid cancer following childhood exposure to external radiation or internal radiation due to iodine-131 $\left({ }^{131} \mathrm{I}\right)$ from the Chernobyl nuclear power plant accident on 26 April 1986 is now well established (UNSCEAR, 2013; Bogdanova et al, 2014a). The largest increase in thyroid cancer was observed among subjects 18 years or younger at the time of the accident. Children received higher thyroid radiation doses on average due to their smaller thyroid mass and higher rates of milk consumption, the main route of ${ }^{131}$ I exposure, and their increased sensitivity to the carcinogenic effects of thyroid irradiation compared with adults (UNSCEAR, 2010, 2013). Papillary thyroid carcinoma (PTC) is the main histological type of post-Chernobyl thyroid cancer (Williams, 2008; Livolsi et al, 2011; Demidchik et al, 2012; Bogdanova et al, 2014a).

A number of histopathological and molecular studies have examined post-Chernobyl thyroid cancer (Bogdanova et al, 1999, 2006; Hess et al, 2011; Livolsi et al, 2011; Abend et al, 2012; Leeman-Neill et al, 2013, 2014; Selmansberger et al, 2014, 2015; Zablotska et al, 2015). However, data on how the histopathological characteristics of PTCs are related to radiation dose and genetic alterations are limited. A recent Belarusian-American thyroid screening study (BelAm) reported that higher ${ }^{131} \mathrm{I}$ doses were associated with a higher frequency of solid or diffuse-sclerosing variants of PTC and histopathological features of cancer aggressiveness, such as lymph vessel invasion, intrathyroidal spreading, and multifocality (Zablotska et al, 2015). We previously reported the results of a detailed histopathological analysis, without considering individual ${ }^{131} \mathrm{I}$ doses, of 56 thyroid carcinomas diagnosed in a Ukrainian-American cohort (UkrAm) in the first cycle of thyroid screening examinations conducted during 1998-2000 (Bogdanova et al, 2006; Bozhok et al, 2009). The BelAm and UkrAm studies had similar designs, methods of screening, and estimations of ${ }^{131}$ I dose (Stezhko et al, 2004; Tronko et al, 2006). Since 2000, 3 additional cycles of screening examinations have been completed in this UkrAm cohort, and 65 new cases of thyroid cancer have been identified. Analysis of radiation risk demonstrated a significant ${ }^{131}$ I-related excess persisting two decades following the accident (Brenner et al, 2011). The objectives of the current analysis were three-fold: (1) to evaluate associations between ${ }^{131} \mathrm{I}$ dose and histopathological characteristics of PTCs in the UkrAm cohort; (2) to evaluate changes in these characteristics over time from prescreening through the fourth cycle of screening; and (3) to evaluate the associations between common somatic alterations and histopathological characteristics in a subset of carcinomas for which somatic mutation profiling has been performed (Leeman-Neill et al, 2013, 2014).

\section{MATERIALS AND METHODS}

Study population and cases. The study protocol was approved by the Institutional Review Boards of the National Cancer Institute (NCI), Bethesda, MD, USA, and Institute of Endocrinology and Metabolism (IEM), Kyiv, Ukraine. All participants or their guardians (for minors) provided written informed consent. The methods of cohort recruitment and follow-up for both the UkrAm and BelAm cohorts have been described previously (Stezhko et al, 2004; Tronko et al, 2006, 2012). In brief, the UkrAm cohort includes 13243 individuals $<18$ years at the time of the accident who resided in 10 highly contaminated raions (counties) of three northern oblasts (states) of Ukraine (Kyiv, Zhytomyr, and Chernihiv) and underwent direct thyroid radioactivity measurements in May-June 1986. Four consecutive standardised thyroid screenings were implemented in the years 1998-2000, 2001-2003, 2003-2005, and 2005-2007, respectively.

As a result of the 4 screening examinations, 904 individuals were referred for fine needle aspiration biopsy (FNAB), and 849 (94\%) complied between 1998 and 2008. All individuals who had a large, multinodular goiter or whose FNAB report indicated one of the following: 'cancer', 'suspicious for cancer', 'follicular neoplasm', or 'suspicious for follicular neoplasm' (Bozhok et al, 2009) were referred for thyroid surgery $(n=196)$. By 31 December 2008, 167 individuals (85\%) had undergone surgery. In addition, 49 individuals underwent surgery before the first screening started in October 1998, and histological samples were available for 20 of these individuals. Thus, the total number of operated cohort members with available histopathological samples was 187 . Postoperative study of paraffin sections or intraoperative evaluation of frozen sections (for cases 'suspicious for cancer') was performed at the Laboratory of Morphology of Endocrine System of the IEM (Bogdanova et al, 2006). All histopathological diagnoses established according to the World Health Organisation (WHO) classification (Delellis, 2004) were additionally reviewed by the International Pathology Panel of the Chernobyl Tissue Bank (CTB) (Williams, 2000). The PTCs were further classified according to the dominant histological pattern into three groups: classic papillary, follicular, or solid (when approximately $>50 \%$ of the slide's surface had the corresponding structure). In addition, PTCs were subdivided into main histological variants according to the WHO classification: classic papillary, follicular, solid, diffuse-sclerosing, Warthin-like (when $>80 \%$ of the slide's surface had the corresponding structure), or mixed (when the tumour was composed of a combination of at least two patterns in nearly equal proportions). Tumour stage was characterised according to the 7th edition of the TNM classification system (Sobin et al, 2010).

For 65 PTCs diagnosed during the first through fourth screening cycles, RNA and DNA aliquots extracted from fresh frozen tissue were previously used in focused genetic profiling (Leeman-Neill et al, 2013, 2014). In the present study, we analysed the associations between common somatic alterations and histopathological characteristics.

Dosimetry. Estimated thyroid doses due to ${ }^{131} \mathrm{I}$ intake based on the interview data obtained at the first screening of the UkrAm cohort (Likhtarev et al, 2006) were subsequently revised and improved in a second round of interviews (Likhtarov et al, 2014). Doses were estimated based on (1) direct radioactivity measurements in the thyroid gland taken within 2 months of the accident; (2) ecological and biokinetic models used to assess the temporal variation of ${ }^{131}$ I radioactivity in the thyroid; and (3) information on individual behaviour and dietary habits obtained in personal interviews. The revised thyroid doses were improved based on (1) new estimates of daily ${ }^{131} \mathrm{I}$ and ${ }^{137} \mathrm{Cs}$ ground deposition densities in all places of residence (Talerko, 2005); (2) correction of the response of thyroid detectors used for direct thyroid measurements to the contribution of radiocaesiums $\left({ }^{134} \mathrm{Cs},{ }^{136} \mathrm{Cs},{ }^{137} \mathrm{Cs}\right)$ incorporated in the human body; (3) the use of age-, sex-, and region-specific thyroid mass data derived from autopsy measurements and measurements of thyroid volume performed in the 1990s in Ukraine by the Sasakawa Memorial Health Foundation (Likhtarov et al, 2013); (4) modified dosimetry questionnaires to collect detailed information on personal behaviour, that is, relocation history; consumption of contaminated milk, dairy products and leafy vegetables; and administration of stable iodine.

Statistical analysis. We assessed the trends in the demographic and histopathological characteristics of the PTCs over five time periods (from prescreening to fourth screening) as follows. For continuous variables (e.g., age and ${ }^{131} \mathrm{I}$ dose), changes over time were evaluated using linear regression models. For categorical variables with multiple outcomes (e.g., dominant histological pattern and histological variant), changes over time were evaluated using polytomous logistic regression models. For binary outcomes (e.g., sex and the presence of capsule), polytomous regression was reduced to binary logistic regression. For both linear regression and 
logistic regression models, we conducted tests of univariate linear trends and tests of linear trends adjusted for age at surgery (i.e., measure of attained age), a major factor underlying the risk of thyroid cancer and its characteristics in unexposed populations.

To evaluate the associations between individual histopathological characteristics and ${ }^{131}$ I thyroid dose, we used logistic regression models. We estimated odds ratios (ORs) for each characteristic with four dose categories chosen to ensure a reasonable distribution of cases $(\leqslant 0.30,0.31-1.00,1.01-2.00, \geqslant 2.01$ gray (Gy)) using $\leqslant 0.30 \mathrm{~Gy}$ as the referent category. We evaluated continuous dose trends based on linear and linear-quadratic (on a log scale) dose-response models. We evaluated the linear-quadratic trend because our previous analyses of dose-response for chromosomal rearrangements suggested non-linearity (LeemanNeill et al, 2013). All dose-response analyses were adjusted for age at surgery unless specified otherwise.

To evaluate the associations between histopathological characteristics and genetic alterations in the subset of cases, we used standard approaches and fitted logistic regression models to several binary outcomes (Domingo et al, 2013; Ewens et al, 2014). The outcomes of interest were defined as tumours with point mutations (in BRAF, HRAS, KRAS, or NRAS genes) vs no point mutations or chromosomal rearrangements (RET/PTC1, RET/PTC3, PAX8/ $P P A R \gamma$, or ETV6-NTRK3) vs no chromosomal rearrangements. The associations with histopathological characteristics were adjusted for sex, oblast of residence in 1986, and ${ }^{131} \mathrm{I}$ dose (in addition to age at surgery) because these factors were significantly associated with both types of genetic alterations in previous analyses (Leeman-Neill et al, 2013). We also compared histopathological characteristics in cases with chromosomal rearrangements and point mutations directly using the heterogeneity test described by Pierce and Preston (1993).

Analyses were conducted using SAS version 9.3 software (SAS Institute Inc, 2012). All tests were two-sided and likelihood ratiobased; $P<0.05$ was considered as statistically significant. Analyses with very small numbers of outcomes $(<5$ per cell) were conducted using exact logistic regression methods.

\section{RESULTS}

Thyroid carcinoma was identified in 121 (64.7\%) of the 187 individuals who underwent surgery by the end of 2008 and for whom histopathological samples were available. In all, 11 thyroid carcinomas were removed before the first screening (i.e., prescreening), 45 following the first screening (cycle 1), 32 following the second screening (cycle 2), 17 following the third screening (cycle 3), and 16 following the fourth screening (cycle 4) (Table 1). Overall, PTC was identified in 115 of 121 cases $(95.0 \%)$, follicular thyroid carcinoma (FTC) in 5 cases $(4.1 \%)$, and medullary thyroid carcinoma (MTC) in 1 case $(0.9 \%)$. One patient who underwent surgery before the first screening had both PTC and small MTC (with MTC described as concomitant thyroid cancer). No cases of poorly differentiated or anaplastic carcinoma were identified. All further analyses were limited to PTCs.

Changes in the characteristics of PTCs over time. Most PTC cases were female, and the proportion of females did not significantly vary over time (Table 1 ). More than $60 \%$ of all PTC cases were children who were $<10$ years old at the time of the Chernobyl accident. The youngest age at exposure was observed in the prescreening cases, and there was no significant trend in age at exposure over time $(P=0.479)$. However, we observed a significant increase in age at surgery over time $(P=0.002$, Table 1$)$. We also observed a significant decrease in ${ }^{131} \mathrm{I}$ thyroid dose over time, although this trend did not persist after adjustment for age at surgery $(P=0.124)$.

The size of PTC upon histopathology ranged from 1 to $50.0 \mathrm{~mm}$; the average size (in the largest dimension) decreased significantly from $23.6 \mathrm{~mm}$ in prescreening cases to $8.4 \mathrm{~mm}$ in cycle 4 cases $(P<0.001)$, whereas the corresponding frequency of PTCs $>10.0 \mathrm{~mm}$ decreased from $100 \%$ to $33.3 \%(P<0.001$, Table 2$)$. The decreasing trends in tumour size distribution remained highly significant after adjustment for age at surgery (Table 2).

Throughout the study, non-encapsulated PTCs were more common. Whereas the frequency of fully encapsulated PTCs was lowest among prescreening cases and highest among cycle 4 cases (Table 2), no significant time trend was observed $(P=0.892)$. Similarly, we observed no significant trend in the proportion of PTCs classified according to dominant histological pattern or histological variant $(P=0.686$ and $P=0.653$, respectively, Table 2).

After controlling for age at surgery, there was evidence of a significant increase over time in the proportion of PTCs with intrathyroidal spreading $(P=0.014$, Table 3$)$. Although the decreasing trend in extrathyroidal extension with time was not significant $(P=0.351)$, trends for other invasive tumour properties were significant, that is, lymphatic/vascular invasion $(P=0.005)$ and combined characteristics of tumour invasiveness (i.e., at least one of the following: extrathyroidal extension, lymphatic/vascular invasion, regional lymph-node and distant lung metastases vs none) $(P=0.026$, Table 3$)$. Interestingly, no distant metastases (M1) were detected in either cycle 3 or 4 cases (Table 3 ). Signs of multifocal growth were noted in cycle 1, 2, and 4 cases, although no evidence of a significant trend was observed $(P=0.601)$. In most multifocal PTCs, the structure and degree of encapsulation of other tumour foci differed from the main lesion (not shown). The increase in the proportion of PTCs with concomitant benign thyroid pathology over time was not significant after adjustment for age $(P=0.295$, Table 3$)$. In each cycle of screening, there were

Table 1. General characteristics of 115 PTC cases $^{a}$

\begin{tabular}{|c|c|c|c|c|c|c|c|}
\hline & Prescreening & Cycle 1 & Cycle 2 & Cycle 3 & Cycle 4 & & \\
\hline Characteristic & $\begin{array}{c}n(\%) \text { or } \\
\text { mean (s.d.) }\end{array}$ & $\begin{array}{c}n(\%) \text { or } \\
\text { mean (s.d.) }\end{array}$ & $\begin{array}{c}n(\%) \text { or } \\
\text { mean (s.d.) }\end{array}$ & $\begin{array}{c}n(\%) \text { or } \\
\text { mean (s.d.) }\end{array}$ & $\begin{array}{c}n(\%) \text { or } \\
\text { mean (s.d.) }\end{array}$ & $P^{b}$ & $P$ \\
\hline Female & $7(63.6)$ & $29(67.4)$ & $15(50.0)$ & $11(68.8)$ & $9(60.0)$ & 0.712 & \\
\hline Age at exposure, years & $4.9(5.1)$ & $8.5(4.8)$ & $9.3(4.8)$ & $7.4(5.4)$ & $8.2(3.9)$ & 0.479 & \\
\hline Age at surgery, years & $14.0(5.6)$ & $23.2(5.1)$ & $26.5(5.1)$ & $26.7(5.6)$ & $29.0(4.4)$ & $<0.001$ & $0.002^{c}$ \\
\hline${ }^{131}$ I thyroid dose, Gy & $3.4(3.8)$ & $1.6(2.3)$ & $1.0(2.2)$ & $0.7(1.0)$ & $0.4(0.6)$ & $<0.001$ & $0.124^{d}$ \\
\hline Total & 11 & 43 & 30 & 16 & 15 & & \\
\hline \multicolumn{8}{|c|}{ 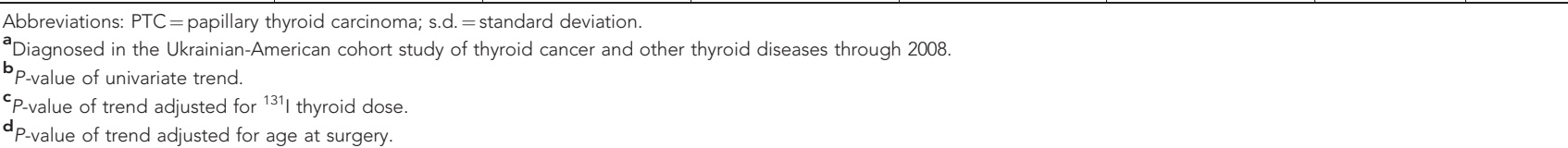 } \\
\hline
\end{tabular}


Table 2. Histopathological characteristics of 115 PTC cases $^{a}$

\begin{tabular}{|c|c|c|c|c|c|c|c|}
\hline & Prescreening & Cycle 1 & Cycle 2 & Cycle 3 & Cycle 4 & & \\
\hline Characteristic & $\begin{array}{c}n(\%) \text { or } \\
\text { mean (s.d.) }\end{array}$ & $\begin{array}{c}n(\%) \text { or } \\
\text { mean (s.d.) }\end{array}$ & $\begin{array}{c}n(\%) \text { or } \\
\text { mean (s.d.) }\end{array}$ & $\begin{array}{c}n(\%) \text { or } \\
\text { mean (s.d.) }\end{array}$ & $\begin{array}{c}n(\%) \text { or } \\
\text { mean (s.d.) }\end{array}$ & $P^{b}$ & $P^{c}$ \\
\hline Tumour size, $\mathrm{mm}$ & $23.6(13.6)$ & $16.9(9.6)$ & $11.7(5.9)$ & $10.9(5.9)$ & $8.4(3.9)$ & $<0.001$ & $<0.001$ \\
\hline $1-10$ & 0 & $10(23.3)$ & $12(40.0)$ & $8(50.0)$ & $10(66.7)$ & & \\
\hline $11-50$ & $11(100.0)$ & $33(76.7)$ & $18(60.0)$ & $8(50.0)$ & 5 (33.3) & $<0.001$ & $<0.001$ \\
\hline \multicolumn{8}{|c|}{ Presence of capsule } \\
\hline No & $10(90.9)$ & $36(83.7)$ & $23(76.7)$ & $14(87.5)$ & $10(66.7)$ & & \\
\hline Yes & $1(9.1)$ & $7(16.3)$ & 7 (23.3) & $2(12.5)$ & 5 (33.3) & 0.195 & 0.892 \\
\hline \multicolumn{8}{|c|}{ Dominant pattern } \\
\hline Papillary & $3(27.3)$ & $14(32.6)$ & $15(50.0)$ & $9(56.3)$ & $4(26.7)$ & & \\
\hline Follicular & $3(27.3)$ & $22(51.2)$ & $10(33.3)$ & $5(31.3)$ & $8(53.3)$ & & \\
\hline Solid & $5(45.5)$ & $7(16.3)$ & $5(16.7)$ & $2(12.5)$ & $3(20.0)$ & 0.548 & 0.686 \\
\hline \multicolumn{8}{|c|}{ Histological variant } \\
\hline Papillary & 0 & $8(18.6)$ & $8(26.7)$ & $2(12.5)$ & $2(13.3)$ & & \\
\hline Follicular & $2(18.2)$ & $14(32.6)$ & 7 (23.3) & $3(18.8)$ & $3(20.0)$ & & \\
\hline Solid & $3(27.3)$ & 5 (11.6) & $3(10.0)$ & 0 & $1(6.7)$ & & \\
\hline Mixed & $4(36.4)$ & $16(37.2)$ & $12(40.0)$ & $10(62.5)$ & $9(60.0)$ & & \\
\hline Diffuse-sclerosing & $2(18.2)$ & 0 & 0 & 0 & 0 & & \\
\hline Warthin-like & 0 & 0 & 0 & $1(6.3)$ & 0 & 0.132 & 0.653 \\
\hline
\end{tabular}

Table 3. Invasive properties and benign concomitant thyroid pathology of 115 PTC cases ${ }^{a}$

\begin{tabular}{|c|c|c|c|c|c|c|c|}
\hline & Prescreening & Cycle 1 & Cycle 2 & Cycle 3 & Cycle 4 & & \\
\hline Characteristic & $n(\%)$ & $n(\%)$ & $n(\%)$ & $n(\%)$ & $n(\%)$ & $P^{\mathrm{b}}$ & $P^{c}$ \\
\hline \multicolumn{8}{|c|}{ Intrathyroidal spreading } \\
\hline No & $3(27.3)$ & $12(27.9)$ & $7(23.3)$ & $1(6.3)$ & $2(13.3)$ & & \\
\hline Yes & $8(72.7)$ & $31(72.1)$ & $23(76.7)$ & $15(93.8)$ & $13(86.7)$ & 0.105 & 0.014 \\
\hline \multicolumn{8}{|c|}{ Extrathyroidal extension } \\
\hline No $(T 1 \text { or T2) })^{d}$ & $7(63.6)$ & $24(55.8)$ & $25(83.3)$ & $10(62.5)$ & $14(93.3)$ & & \\
\hline Yes $(\mathrm{T} 3)^{d}$ & $4(36.4)$ & $19(44.2)$ & $5(16.7)$ & $6(37.5)$ & $1(6.7)$ & 0.025 & 0.351 \\
\hline \multicolumn{8}{|c|}{ Lymphatic/vascular invasion } \\
\hline No & 0 & $16(37.2)$ & $15(50.0)$ & $7(43.8)$ & $13(86.7)$ & & \\
\hline Yes & $11(100.0)$ & $27(62.8)$ & $15(50.0)$ & $9(56.3)$ & $2(13.3)$ & $<0.001$ & 0.005 \\
\hline \multicolumn{8}{|c|}{ Lymph-node metastases } \\
\hline No $(\mathrm{NO})^{\mathrm{d}}$ & $4(36.4)$ & $28(65.1)$ & $24(80.0)$ & $12(75.0)$ & $13(86.7)$ & & \\
\hline Yes (N1a or N1b) & $7(63.6)$ & $15(34.9)$ & $6(20.0)$ & $4(25.0)$ & $2(13.3)$ & 0.009 & 0.202 \\
\hline \multicolumn{8}{|c|}{ Distant lung metastases } \\
\hline No $(\mathrm{M} 0)^{\mathrm{d}}$ & $10(90.9)$ & $40(93.0)$ & $29(96.7)$ & $16(100.0)$ & $15(100.0)$ & & \\
\hline Yes (M1) & $1(9.1)$ & $3(7.0)$ & $1(3.3)$ & 0 & 0 & 0.125 & 0.416 \\
\hline \multicolumn{8}{|c|}{ Combined invasiveness $^{\mathrm{e}}$} \\
\hline None & 0 & $13(30.2)$ & $12(40.0)$ & $5(3 \mid .2)$ & $12(80.0)$ & & \\
\hline At least one & $11(100.0)$ & $30(69.8)$ & $18(60.0)$ & $11(68.8)$ & $3(20.0)$ & $<0.001$ & 0.026 \\
\hline \multicolumn{8}{|l|}{ Multifocality } \\
\hline No & 11(100.0) & $36(83.7)$ & $25(83.3)$ & $16(100.0)$ & $13(86.7)$ & & \\
\hline Yes $\left(T_{m}\right)^{d}$ & 0 & 7 (16.3) & $5(16.7)$ & 0 & $2(13.3)$ & 0.906 & 0.601 \\
\hline \multicolumn{8}{|c|}{ Benign concomitant thyroid pathology } \\
\hline No & $11(100.0)$ & $31(72.1)$ & $19(63.3)$ & $10(62.5)$ & $8(53.3)$ & & \\
\hline Yes & 0 & $12(27.9)$ & $11(36.7)$ & $6(37.5)$ & $7(46.7)$ & 0.021 & 0.296 \\
\hline 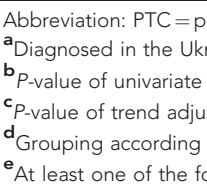 & $\begin{array}{l}\text { thyroid carcinoma. } \\
\text { American cohort stud } \\
\text { r age at surgery. } \\
\text { our-node-metastasis }\end{array}$ & yroid cancer & nyroid disease & 2008. & & & \\
\hline
\end{tabular}

PTCs associated with the presence of follicular adenoma, hyperplastic nodule(s), or chronic thyroiditis, and no particular pattern was observed for the specific presence of any one of these pathologies (not shown).
Associations between histopathological characteristics of PTCs and ${ }^{131}$ I dose. None of the individual histopathological characteristics of PTCs, that is, intrathyroidal spreading, extrathyroidal extension, and lymphatic/vascular invasion or metastases, was 
Table 4. Dose-response associations for invasive properties and benign concomitant thyroid pathology of 115 PTC cases ${ }^{a}$

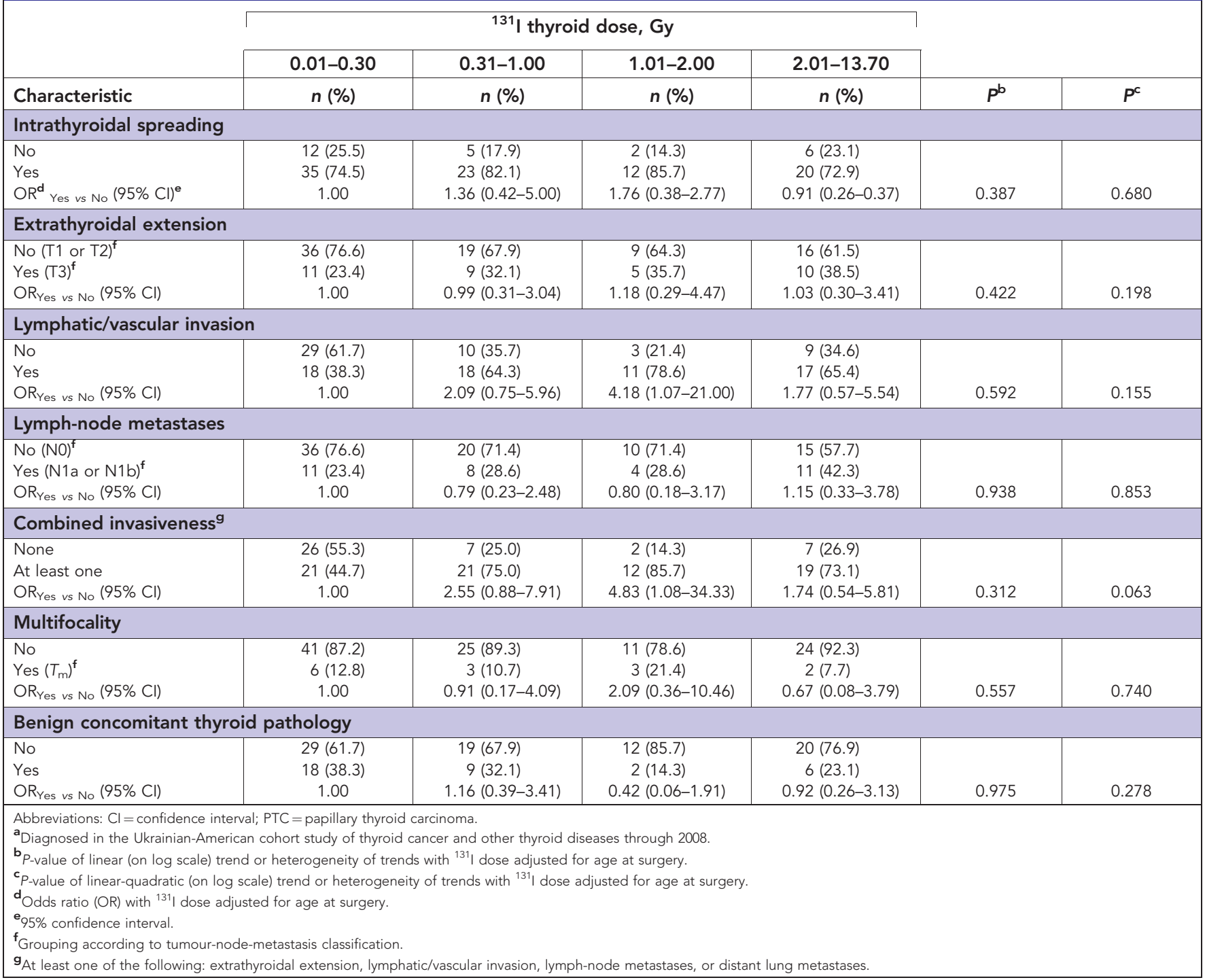

significantly associated with ${ }^{131} \mathrm{I}$ dose either in categorical or in continuous analyses of the dose-response (Supplementary Table 1 and Table 4). However, for lymphatic/vascular invasion and for the combined characteristics of tumour invasiveness, the ORs with ${ }^{131} \mathrm{I}$ dose categories (higher than $0.30 \mathrm{~Gy}$ ) were consistently $>1$ and, for the combined characteristics of tumour invasiveness, there was a borderline significant linear-quadratic trend with dose $(P=0.063)$ increasing at low-to-moderate doses and decreasing at high doses (Table 4).

Associations between the histopathological characteristics of PTCs and genetic alterations. Supplementary Table 2 summarises the distribution of 65 PTCs with specific genetic alterations according to the selected histopathological characteristics. There was a high proportion of solid variant tumours among RET/PTC3-positive PTCs, whereas there was a high proportion of follicular variant tumours among ETV6-NTRK3-positive PTCs. In addition, both RET/PTC3- and ETV6-NTRK3-positive PTCs had a high proportion of tumours with lymphatic/vascular invasion. Both PTCs positive for $P A X 8 / P P A R \gamma$ rearrangement were of the follicular variant.

Table 5 presents the ORs for PTCs grouped according to the presence or absence of point mutations (BRAF or RAS) or chromosomal rearrangements (RET/PTC, PAX8/PPAR $\gamma$, or ETV6-NTRK3).
The PTCs with chromosomal rearrangements tended to have increased ORs with invasive tumour properties (Table 5). In particular, the OR associated with lymphatic/vascular invasion was significantly elevated $(\mathrm{OR}=5.85 ; 95 \%$ CI: $1.43-31.75)$. In general, the patterns of ORs in relation to various histopathological characteristics of PTCs with chromosomal rearrangements were opposite those for PTCs with point mutations (Table 5). When compared directly, tumours with chromosomal rearrangements were significantly more likely to have intrathyroidal spreading $(P=0.020)$ and lymphatic/vascular invasion $(P=0.008)$ than tumours with point mutations (Table 5).

\section{DISCUSSION}

In a large thyroid screening cohort in Ukraine comprising individuals exposed to ${ }^{131} \mathrm{I}$ from the Chernobyl accident during childhood or adolescence, PTC continues to be the main tumour type, regardless of the screening cycle. We observed strong, significant trends in decreasing tumour size and invasive properties of PTCs with each subsequent screening after adjustment for increasing age at surgery. Combining all PTCs diagnosed in the cohort by the end of 2008, we identified a borderline significant non-linear ${ }^{131} \mathrm{I}$ dose response for the 
Table 5. Associations between point mutations or chromosomal rearrangements and histopathological characteristics of 65 PTCs $^{\mathrm{a}}$

\begin{tabular}{|c|c|c|c|c|c|c|c|c|c|}
\hline & $\begin{array}{c}\text { BRAF }^{-} \\
\text {and RAS }\end{array}$ & $\begin{array}{l}\text { BRAF }^{+} \\
\text {or RAS }\end{array}$ & & & $\begin{array}{l}\text { Chromosomal } \\
\text { rearrangement }\end{array}$ & $\begin{array}{c}\text { Chromosomal } \\
\text { rearrangement }\end{array}$ & & & \\
\hline Characteristic & $n(\%)$ & $n(\%)$ & $O^{b}$ & $95 \% \mathrm{Cl}^{\mathrm{c}}$ & $n(\%)$ & $n(\%)$ & $O R^{b}$ & $95 \% \mathrm{Cl}^{\mathrm{c}}$ & $P^{d}$ \\
\hline \multicolumn{10}{|c|}{ Tumour size, mm } \\
\hline $1-10$ & $42(82.4)$ & $11(78.6)$ & 1.00 & \multirow[b]{2}{*}{$0.42-116.52$} & $22(73.3)$ & $28(87.5)$ & 1.00 & & \\
\hline $\begin{array}{l}11-50 \\
P^{e}\end{array}$ & $9(17.7)$ & $3(21.4)$ & $\begin{array}{l}5.98 \\
0.186\end{array}$ & & $8(26.7)$ & $4(12.5)$ & $\begin{array}{l}0.26 \\
0.101\end{array}$ & $0.04-1.29$ & 0.088 \\
\hline \multicolumn{10}{|c|}{ Presence of capsule } \\
\hline No & $44(86.3)$ & $9(64.3)$ & 1.00 & \multirow{3}{*}{$0.57-154.42$} & $22(73.3)$ & $29(90.6)$ & 1.00 & & \\
\hline Yes & $7(13.7)$ & $5(35.7)$ & 6.82 & & $8(26.7)$ & $3(9.4)$ & 0.32 & $0.04-1.96$ & 0.063 \\
\hline$P$ & & & 0.132 & & & & 0.219 & & \\
\hline \multicolumn{10}{|c|}{ Dominant pattern } \\
\hline Papillary & $17(33.3)$ & $7(50.0)$ & 1.19 & \multirow[t]{2}{*}{$0.13-10.42$} & $11(36.7)$ & $12(37.5)$ & 2.44 & $0.58-11.51$ & \multirow{4}{*}{0.858} \\
\hline Follicular & $25(49.0)$ & $4(28.6)$ & 1.00 & & $15(50.0)$ & $14(43.8)$ & 1.00 & & \\
\hline Solid & $9(17.7)$ & $3(21.4)$ & 0.37 & $0.01-6.52$ & 4 (13.3) & $6(18.8)$ & 2.74 & $0.37-23.76$ & \\
\hline & & & 0.736 & & & & 0.387 & & \\
\hline \multicolumn{10}{|c|}{ Histological variant } \\
\hline Papillary & $6(11.8)$ & $5(35.7)$ & 7.22 & \multirow[t]{2}{*}{$0.45-184.90$} & $7(23.3)$ & $3(9.4)$ & 0.84 & \multirow[t]{2}{*}{$0.11-6.37$} & \multirow{5}{*}{0.221} \\
\hline Follicular & $17(33.3)$ & $2(14.3)$ & 1.00 & & $9(30.0)$ & $10(31.3)$ & 1.00 & & \\
\hline Solid & $5(9.8)$ & $2(14.3)$ & 2.30 & $0.04-134.88$ & $3(10.0)$ & $4(12.5)$ & 0.92 & $0.07-12.74$ & \\
\hline Mixed & $23(45.1)$ & $5(35.7)$ & 0.54 & $0.04-6.79$ & $11(36.7)$ & $15(46.9)$ & 2.86 & $0.64-14.82$ & \\
\hline$P$ & & & 0.266 & & & & 0.412 & & \\
\hline \multicolumn{10}{|c|}{ Intrathyroidal spreading } \\
\hline No & $9(17.7)$ & $6(42.9)$ & 1.00 & \multirow{3}{*}{$0.01-1.50$} & $8(26.7)$ & $4(12.5)$ & 1.00 & \multirow{3}{*}{$0.48-17.22$} & \multirow{3}{*}{0.020} \\
\hline Yes & $42(82.4)$ & $8(57.1)$ & 0.14 & & $22(73.3)$ & $28(87.5)$ & 2.68 & & \\
\hline$P$ & & & 0.105 & & & & 0.261 & & \\
\hline \multicolumn{10}{|c|}{ Extrathyroidal extension } \\
\hline No $(T 1 \text { or } T 2)^{t}$ & $27(52.9)$ & $12(85.7)$ & 1.00 & & $18(60.0)$ & $17(53.1)$ & 1.00 & & \\
\hline Yes $(T 3)^{f}$ & $24(47.1)$ & $2(14.3)$ & 0.33 & $0.03-2.58$ & $12(40.0)$ & $15(46.9)$ & 1.37 & $0.36-5.33$ & 0.172 \\
\hline$P$ & & & 0.288 & & & & 0.643 & & \\
\hline Lymphatic/vascu & nvasion & & & & & & & & \\
\hline No & $16(31.4)$ & $9(64.3)$ & 1.00 & & $15(50.0)$ & $9(28.1)$ & 1.00 & & \\
\hline Yes & 35 (68.6) & $5(35.7)$ & 0.14 & $0.01-0.95$ & $15(50.0)$ & 23 (71.9) & 5.85 & $1.43-31.75$ & 0.008 \\
\hline$P$ & & & 0.044 & & & & 0.013 & & \\
\hline Lymph-node me & ases & & & & & & & & \\
\hline No $(\mathrm{NO})^{f}$ & $33(64.7)$ & $11(78.6)$ & 1.00 & & $21(70.0)$ & $20(62.5)$ & 1.00 & & \\
\hline Yes (N1a or N1b) ${ }^{f}$ & 18 (35.3) & 3 (21.4) & 0.66 & $0.07-5.33$ & 9 (30.0) & $12(37.5)$ & 1.33 & $0.38-4.78$ & 0.486 \\
\hline$P$ & & & 0.694 & & & & 0.654 & & \\
\hline Combined invas & $e^{g} s^{g}$ & & & & & & & & \\
\hline None & $9(17.7)$ & $7(50.0)$ & 1.00 & & $9(30.0)$ & 6 (18.8) & 1.00 & & \\
\hline At least one & $42(82.3)$ & $7(50.0)$ & 0.23 & $0.02-1.86$ & $21(70.0)$ & $26(81.3)$ & 2.08 & $0.47-10.36$ & 0.087 \\
\hline$P$ & & & 0.165 & & & & 0.336 & & \\
\hline Multifocality & & & & & & & & & \\
\hline No & $44(86.3)$ & $11(78.6)$ & 1.00 & & $28(93.3)$ & 25 (78.1) & 1.00 & & \\
\hline Yes $\left(T_{m}\right)^{f}$ & 7 (13.7) & $3(11.4)$ & 4.12 & $0.39-52.06$ & $2(6.7)$ & 7 (21.9) & 4.32 & $0.64-42.85$ & 0.799 \\
\hline$P$ & & & 0.237 & & & & 0.139 & & \\
\hline Benign concomi & thyroid pat & ogy & & & & & & & \\
\hline No & $42(82.4)$ & $12(85.7)$ & 1.00 & & $26(86.7)$ & 27 (84.4) & 1.00 & & \\
\hline Yes & $9(17.7)$ & $2(14.3)$ & 0.26 & $0.02-2.61$ & 4 (13.3) & 5 (15.6) & 3.74 & $0.55-31.03$ & 0.094 \\
\hline$P$ & & & 0.266 & & & & 0.179 & & \\
\hline & e interval; PTC & lary thyroid & & & & & & & \\
\hline & & & & & rough 2008. & & & & \\
\hline${ }^{\mathrm{b}}$ Odds ratio (OR) adjus & 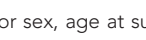 & blo of & & & & & & & \\
\hline${ }^{c} 95 \%$ confidence inten & & & & & & & & & \\
\hline${ }_{P}{ }_{P \text {-value of heterogen }}$ & $f$ adjusted ORs & romosome rea & ement-pc & e PTCs relativ & to BRAF/RAS-positive & & & & \\
\hline${ }^{e_{P} \text {-value of heterogene }}$ & adjusted ORs fc & omosome rearr & nent-pos & PTCs relative & chromosome rearran & ent-negative PTCs or $B$ & $=/ R A S-p c$ & e PTCs relati & BRAFI \\
\hline RAS-negative PTCs. & & & & & & & & & \\
\hline fGrouping according t & 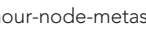 & Wicis & & & & & & & \\
\hline
\end{tabular}

combined characteristics of tumour invasiveness, defined as the presence of extrathyroidal extension, lymphatic/vascular invasion, or metastases. In a subset of tumours for which somatic mutation profiling was performed, irrespective of ${ }^{131} \mathrm{I}$ dose, we observed a significantly increased $O R$ with the presence of lymphatic/vascular invasion for cases with common chromosomal rearrangements relative to cases without chromosomal rearrangements or to cases with $B R A F / R A S$ point mutations.

The differences in the histopathological or invasive properties of thyroid carcinomas in irradiated populations and unirradiated 
populations and the relationships between these properties and radiation dose have not been clearly elucidated. Several studies of post-Chernobyl thyroid cancers have implied that radiation-related cases tend to be more aggressive and/or advanced at presentation, particularly in paediatric cases (Bogdanova et al, 1999; Tuttle et al, 2011), although others have demonstrated that the invasive properties of post-Chernobyl PTCs are related to young age at onset (Tuttle et al, 2011). Specifically, a study of 168 PTCs $(<15$ years of age at diagnosis) in Ukraine detected a significant increase in the proportion of aggressive solid-follicular variant tumours with higher average settlement-specific ${ }^{131}$ I doses (Bogdanova et al, 1999). Another study of 125 post-Chernobyl PTC cases diagnosed in Ukraine (15-23 years of age at diagnosis) and a comparable number of age-matched 'unexposed' cases born after the accident reported that the odds of extrathyroidal invasion were approximately three times higher in cases 'exposed' to ${ }^{131} \mathrm{I}$ than in 'unexposed' cases (Bogdanova et al, 2014b). A recent study of 158 PTCs diagnosed in the thyroid screening cohort in Belarus (BelAm) identified a significant linear association between several characteristics of tumour invasiveness (i.e., lymphatic invasion, intrathyroidal spreading, and multifocality) and individual, measurement-based ${ }^{131} \mathrm{I}$ thyroid doses in analyses adjusted for age at surgery (Zablotska et al, 2015). In the current study, which was designed, conducted, and analysed according to similar methods (Stezhko et al, 2004; Tronko et al, 2006), we observed a borderline significant linear-quadratic association for the combined characteristics of tumour invasiveness; this association seemed to be driven mainly by lymphatic/vascular invasion. In contrast to the BelAm study, no significant dose-response associations with other characteristics of tumour invasiveness were observed in the UkrAm study.

The apparent differences between the UkrAm and BelAm studies may be due to the smaller number of cases (115 vs 158) and consequently lower statistical power of the UkrAm study. In addition, the proportion of solid variant PTCs, which are associated with more aggressive tumour properties, was lower in the UkrAm study (10\% vs 28\%) despite the generally comparable distribution of sex, age, and ${ }^{131} \mathrm{I}$ dose (Zablotska et al, 2015). The reasons for this discrepancy are unclear but are likely to be important because the frequency of solid or diffuse-sclerosing variants of PTC (of which $92 \%$ were solid variant PTC) increased significantly with ${ }^{131} \mathrm{I}$ dose in the BelAm study. The extent to which this relationship may have confounded the dose-related increase in aggressive PTC properties observed in the BelAm study remains to be determined. The differences in the dose-response shape, that is, linear in BelAm and nearly linear-quadratic in UkrAm, must be considered while taking into account the uncertainty of thyroid dose estimates. On average, uncertainties in ${ }^{131}$ I doses were lower in the UkrAm than in the BelAm study (mean GSD 1.55 vs 1.76) but should be formally incorporated into the analysis (Likhtarov et al, 2014; Drozdovitch et al, 2015).

Despite differences in their findings, both the UkrAm and BelAm studies concluded that invasive PTC properties, particularly lymphatic/vascular invasion, may be related to ${ }^{131} \mathrm{I}$ dose. This evidence must be considered in the context of repeated screenings of populations. As screenings in both studies were standardised and conducted irrespective of dose, confounding by screening intensity is unlikely. A dose-response for combined-characteristic of tumour invasiveness was suggested in the UkrAm study, although the proportion of small, less invasive PTCs increased with each screening. Although the BelAm study reported no analyses of invasive tumour characteristics according to individual screening cycles, comparison of prescreening, prevalent (first cycle), and incident (second and third cycles) PTCs revealed similar patterns (Zablotska et al, 2015). There is no doubt that repeated thyroid examinations with sensitive ultrasound devices and FNAB contribute to the early detection of PTCs while they are small and localised.
There is accumulating evidence that the types of somatic mutations in PTC may indicate aetiology (Nikiforov and Nikiforova, 2011). Certain chromosomal rearrangements, for example, RET/PTC, ETV6-NTKR3, and EML4-ALK, may be characteristic of radiation-related thyroid cancer, whereas point mutations in the BRAF or RAS genes may be characteristic of sporadic cancer (Takahashi et al, 2007; Hamatani et al, 2008, 2012; Leeman-Neill et al, 2013, 2014). Our previous findings in a subset of UkrAm cases support this idea (Leeman-Neill et al, 2013, 2014). We reported that the frequency of several chromosomal rearrangements as a group followed a linear-quadratic dose-response, whereas the frequency of the BRAF/RAS mutations was inversely and linearly associated with ${ }^{131}$ I dose (Leeman-Neill et al, 2013). Given that the association between dose and the combined characteristics of PTC invasiveness also followed a concave pattern, we evaluated the associations between somatic mutations and the invasive properties of PTCs.

Much evidence on this subject comes from non-irradiated patients in whom the presence of the BRAF V600E mutation has been associated with aggressive PTC histopathology and adverse clinical outcomes (Kim et al, 2012; Pelizzo et al, 2014). By contrast, some studies of radiation-related post-Chernobyl PTCs have suggested that RET/PTC (particularly RET/PTC3) rearrangements occur frequently in morphologically aggressive solid variant tumours (Rabes et al, 2000; Williams et al, 2004). In our study, five of eight RET/PTC3-positive tumours were of the solid variant, seven had evidence of extrathyroidal extension, and all eight had evidence of lymphatic/vascular invasion. In addition, we observed that PTCs with chromosomal rearrangements were significantly associated with lymphatic/vascular invasion compared with PTCs without chromosomal rearrangements or PTCs with $B R A F / R A S$ point mutations after adjustment for age and ${ }^{131} \mathrm{I}$ dose. Therefore, PTCs with chromosomal rearrangements may be more aggressive (i.e., lymphatic/vascular invasion), regardless of the received thyroid dose and age. Moreover, PTCs with common chromosomal rearrangements and $B R A F / R A S$ point mutations may have both different aetiologies and distinct phenotypes.

Among the major strengths of our study are the availability of measurement-based individual ${ }^{131}$ I thyroid dose estimates, screening according to a standardised protocol and irrespective of dose, high rates of compliance with FNAB and thyroid surgery ( $94 \%$ and $85 \%$, respectively), and histopathological diagnoses based on the review of diagnostic material by an international pathology panel. However, limitations include limited statistical power, availability of genetic data for only a subset of cases (57\%), and a lack of clinical follow-up data.

In conclusion, our study corroborates and extends evidence that the aggressive properties of PTCs diagnosed in individuals exposed to ${ }^{131}$ I from the Chernobyl accident as children or adolescents may be associated with the radiation dose and the presence of chromosomal translocations. The observed dose-response and genotype-phenotype associations require confirmation in largescale studies of radiation-related PTCs. Clinical studies should evaluate whether changes in invasive PTC properties due to irradiation and repeated screening may lead to changes in clinical outcomes.

\section{ACKNOWLEDGEMENTS}

We acknowledge the commitment of our Colleagues at the Institute of Endocrinology and Metabolism (IEM) in Ukraine who performed all four screening examinations, particularly the staff of the Laboratory of Endocrine System Morphology who collected histopathological samples from the Ukrainian-American cohort and staff of the Surgery Department who operated on these 
patients. We also acknowledge our American colleagues, Drs. J Robbins, E Greenebaum, and P O'Kane, who collaborated with us over many years and participated in discussions of clinical and histopathological data. We gratefully acknowledge the confirmation of diagnoses provided by the International Pathology Panel of the Chernobyl Tissue Bank: Professors A Abrosimov, T Bogdanova, G Fadda, J Hunt, M Ito, V Livolsi, J Rosai, and ED Williams. This research was supported by the Intramural Research Program of the National Institutes of Health, National Cancer Institute, and the Department of Energy. The US Nuclear Regulatory Commission provided the initial funds for equipment purchase. The work of Drs. Nikiforov and Leeman-Neill was in part supported by NIH grant R01 CA88041 to YEN; Drs. Zablotska and McConnell by contract NO1-CP-21178 to LBZ and RJM and grant CA132918 to LBZ

\section{CONFLICT OF INTEREST}

The authors declare no conflict of interest.

\section{REFERENCES}

Abend M, Pfeiffer RM, Ruf C, Hatch M, Bogdanova TI, Tronko MD, Riecke A, Hartmann J, Meineke V, Boukheris H, Sigurdson AJ, Mabuchi K, Brenner AV (2012) Iodine-131 dose dependent gene expression in thyroid cancers and corresponding normal tissues following the Chernobyl accident. PLoS One 7(7): e39103.

Bogdanova T, Zurnadzhy L, Livolsi VA, Williams ED, Ito M, Nakashima M, Thomas GA (2014a) Thyroid cancer pathology in Ukraine after Chernobyl. In: Thyroid Cancer in Ukraine After Chernobyl: Dosimetry, Epidemiology, Pathology, Molecular Biology, Tronko MD, Bogdanova TI, Saenko V, Thomas TL, Likhtarov I, Yamashita S (eds) Chapter 4. Nagasaki Association for Hibakushas' Medical Care: Nagasaki, Japan, pp 65-108.

Bogdanova T, Saenko V, Zurnadzhy L, Likhtarov I, Kovgan L, Masiuk S, Kashcheev V, Livolsi V, Williams ED, Ito M, Mine M, Thomas GA, Tronko M, Yamashita S (2014b) Comparative pathological analysis of papillary thyroid carcinoma in age-matched groups of patients born before and after Chernobyl. In: Thyroid Cancer in Ukraine After Chernobyl: Dosimetry, Epidemiology, Pathology, Molecular Biology, Tronko MD, Bogdanova TI, Saenko V, Thomas TL, Likhtarov I, Yamashita S (eds) Chapter 5. Nagasaki Association for Hibakushas' Medical Care: Nagasaki, Japan, pp 109-134.

Bogdanova TI, Kozyritsky V, Tronko M, Likhtarov I, Kairo I, Chepurnoy M, Shpak V (1999) Morphological features and analysis of radiation risk of development of post-Chernobyl thyroid carcinoma in children and adolescents of Ukraine. In: Radiation and Thyroid Cancer, Thomas G, Karaoglou A, Williams ED (eds). World Scientific: Singapore, pp 151-154.

Bogdanova TI, Zurnadzhy LY, Greenebaum E, Mcconnell RJ, Robbins J, Epstein OV, Olijnyk VA, Hatch M, Zablotska LB, Tronko MD (2006) A cohort study of thyroid cancer and other thyroid diseases after the Chornobyl accident: pathology analysis of thyroid cancer cases in Ukraine detected during the first screening (1998-2000). Cancer 107(11): 2559-2566.

Bozhok Y, Greenebaum E, Bogdanova TI, Mcconnell RJ, Zelinskaya A, Brenner AV, Zurnadzhy LY, Zablotska L, Tronko MD, Hatch M (2009) NA cohort study of thyroid cancer and other thyroid diseases after the Chernobyl accident: cytohistopathologic correlation and accuracy of fineneedle aspiration biopsy in nodules detected during the first screening in Ukraine (1998-2000). Cancer 117(2): 73-81.

Brenner AV, Tronko MD, Hatch M, Bogdanova TI, Oliynik VA, Lubin JH, Zablotska LB, Tereschenko VP, Mcconnell RJ, Zamotaeva GA, O'kane P, Bouville AC, Chaykovskaya LV, Greenebaum E, Paster IP, Shpak VM, Ron E (2011) I-131 dose response for incident thyroid cancers in Ukraine related to the Chornobyl accident. Environ Health Perspect 119(7): 933-939.

Delellis RA (2004) World Health Organization Classification of Tumours. Pathology and Genetics of Tumours of Endocrine Organs. IARC Press: Lyon, France.

Demidchik Y, Fridman M, Schmid KW, Reiners C, Biko J, Mankovskaya S (2012) Papillary thyroid cancer in childhood and adolescence with specific consideration of patients after radiation exposure. In: Updates in the Understanding and Management of Thyroid Cancer, Fahey TJ (ed) Chapter 7. InTech: online. pp 163-188. Available from http:// www.intechopen.com/books/updates-in-the-understanding-andmanagement-of-thyroid-cancer/papillary-thyroid-cancer-in-childhoodand-adolescence-with-specific-consideration-of-patients-after.

Domingo E, Ramamoorthy R, Oukrif D, Rosmarin D, Presz M, Wang H, Pulker H, Lockstone H, Hveem T, Cranston T, Danielsen H, Novelli M, Davidson B, Xu ZZ, Molloy P, Johnstone E, Holmes C, Midgley R, Kerr D, Sieber O, Tomlinson I (2013) Use of multivariate analysis to suggest a new molecular classification of colorectal cancer. J Pathol 229(3): 441-448.

Drozdovitch V, Minenko V, Golovanov I, Khrutchinsky A, Kukhta T, Kutsen S, Luckyanov N, Ostroumova E, Trofimik S, Voilleque P, Simon SL, Bouville A (2015) Thyroid dose estimates for a cohort of Belarusian children exposed to (131)I from the Chernobyl accident: assessment of uncertainties. Radiat Res 184: 203-218.

Ewens KG, Kanetsky PA, Richards-Yutz J, Purrazzella J, Shields CL, Ganguly T, Ganguly A (2014) Chromosome 3 status combined with BAP1 and EIF1AX mutation profiles are associated with metastasis in uveal melanoma. Invest Ophthalmol Vis Sci 55(8): 5160-5167.

Hamatani K, Mukai M, Takahashi K, Hayashi Y, Nakachi K, Kusunoki Y (2012) Rearranged anaplastic lymphoma kinase (ALK) gene in adult-onset papillary thyroid cancer amongst atomic bomb survivors. Thyroid 22(11): 1153-1159.

Hamatani K, Eguchi H, Ito R, Mukai M, Takahashi K, Taga M, Imai K, Cologne J, Soda M, Arihiro K, Fujihara M, Abe K, Hayashi T, Nakashima M, Sekine I, Yasui W, Hayashi Y, Nakachi K (2008) RET/PTC rearrangements preferentially occurred in papillary thyroid cancer among atomic bomb survivors exposed to high radiation dose. Cancer Res 68(17): 7176-7182.

Hess J, Thomas G, Braselmann H, Bauer V, Bogdanova T, Wienberg J, Zitzelsberger H, Unger K (2011) Gain of chromosome band 7q11 in papillary thyroid carcinomas of young patients is associated with exposure to low-dose irradiation. Proc Natl Acad Sci USA 108(23): 9595-9600.

Kim SJ, Lee KE, Myong JP, Park JH, Jeon YK, Min HS, Park SY, Jung KC, Koo Do H, Youn YK (2012) BRAF V600E mutation is associated with tumor aggressiveness in papillary thyroid cancer. World J Surg 36(2): 310-317.

Leeman-Neill RJ, Brenner AV, Little MP, Bogdanova TI, Hatch M, Zurnadzy LY, Mabuchi K, Tronko MD, Nikiforov YE (2013) RET/PTC and PAX8/ PPARgamma chromosomal rearrangements in post-Chernobyl thyroid cancer and their association with iodine-131 radiation dose and other characteristics. Cancer 119(10): 1792-1799.

Leeman-Neill RJ, Kelly LM, Liu P, Brenner AV, Little MP, Bogdanova TI, Evdokimova VN, Hatch M, Zurnadzy LY, Nikiforova MN, Yue NJ, Zhang M, Mabuchi K, Tronko MD, Nikiforov YE (2014) ETV6-NTRK3 is a common chromosomal rearrangement in radiation-associated thyroid cancer. Cancer 120(6): 799-807.

Likhtarev I, Bouville A, Kovgan L, Luckyanov N, Voilleque P, Chepurny M (2006) Questionnaire- and measurement-based individual thyroid doses in Ukraine resulting from the Chornobyl nuclear reactor accident. Radiat Res 166(1 Pt 2): 271-286.

Likhtarov I, Kovgan L, Masiuk S, Talerko M, Chepurny M, Ivanova O, Gerasymenko V, Boyko Z, Voilleque P, Drozdovitch V, Bouville A (2014) Thyroid cancer study among Ukrainian children exposed to radiation after the Chornobyl accident: improved estimates of the thyroid doses to the cohort members. Health Phys 106(3): 370-396.

Likhtarov I, Kovgan L, Masiuk S, Chepurny M, Ivanova O, Gerasymenko V, Boyko Z, Voilleque P, Antipkin Y, Lutsenko S, Oleynik V, Kravchenko V, Tronko M (2013) Estimating thyroid masses for children, infants, and fetuses in Ukraine exposed to (131)I from the Chernobyl accident. Health Phys 104(1): 78-86.

Livolsi VA, Abrosimov AA, Bogdanova T, Fadda G, Hunt JL, Ito M, Rosai J, Thomas GA, Williams ED (2011) The Chernobyl thyroid cancer experience: pathology. Clin Oncol (R Coll Radiol) 23(4): 261-267.

Nikiforov YE, Nikiforova MN (2011) Molecular genetics and diagnosis of thyroid cancer. Nat Rev Endocrinol 7(10): 569-580.

Pelizzo MR, Dobrinja C, Casal Ide E, Zane M, Lora O, Toniato A, Mian C, Barollo S, Izuzquiza M, Guerrini J, De Manzini N, Merante Boschin I, Rubello D (2014) The role of BRAF(V600E) mutation as poor prognostic factor for the outcome of patients with intrathyroid papillary thyroid carcinoma. Biomed Pharmacother 68(4): 413-417.

Pierce DA, Preston DL (1993) Joint analysis of site-specific cancer risks for the atomic bomb survivors. Radiat Res 134(2): 134-142.

Rabes HM, Demidchik EP, Sidorow JD, Lengfelder E, Beimfohr C, Hoelzel D, Klugbauer S (2000) Pattern of radiation-induced RET and NTRK1 
rearrangements in 191 post-chernobyl papillary thyroid carcinomas: biological, phenotypic, and clinical implications. Clin Cancer Res 6(3): 1093-1103. SAS Institute Inc (2012) SAS Version 9.3 for Windows: User's Guide. SAS Institute Inc.: Cary, NC, USA.

Selmansberger M, Feuchtinger A, Zurnadzhy L, Michna A, Kaiser JC, Abend M, Brenner A, Bogdanova T, Walch A, Unger K, Zitzelsberger H, Hess J (2014) CLIP2 as radiation biomarker in papillary thyroid carcinoma. Oncogene 34 : 3917-3925.

Selmansberger M, Feuchtinger A, Zurnadzhy L, Michna A, Kaiser JC, Abend M, Brenner A, Bogdanova T, Walch A, Unger K, Zitzelsberger H, Hess J (2015) CLIP2 as radiation biomarker in papillary thyroid carcinoma. Oncogene 34(30): 3917-3925.

Sobin LH, Gospodarowicz MK, Wittekind C. International Union against cancer (2010) TNM Classification of Malignant Tumours. Wiley-Blackwell: Chichester, West Sussex, UK; Hoboken, NJ, USA.

Stezhko VA, Buglova EE, Danilova LI, Drozd VM, Krysenko NA, Lesnikova NR, Minenko VF, Ostapenko VA, Petrenko SV, Polyanskaya ON, Rzheutski VA, Tronko MD, Bobylyova OO, Bogdanova TI, Ephstein OV, Kairo IA, Kostin OV, Likhtarev IA, Markov VV, Oliynik VA, Shpak VM, Tereshchenko VP, Zamotayeva GA, Beebe GW, Bouville AC, Brill AB, Burch JD, Fink DJ, Greenebaum E, Howe GR, Luckyanov NK, Masnyk IJ, Mcconnell RJ, Robbins J, Thomas TL, Voilleque PG, Zablotska LB. Chornobyl Thyroid Diseases Study Group of Belarus, Chornobyl Thyroid Diseases Study Group of Ukraine, Chornobyl Thyroid Diseases Study Group of the USA (2004) A cohort study of thyroid cancer and other thyroid diseases after the Chornobyl accident: objectives, design and methods. Radiat Res 161(4): 481-492.

Takahashi K, Eguchi H, Arihiro K, Ito R, Koyama K, Soda M, Cologne J, Hayashi Y, Nakata Y, Nakachi K, Hamatani K (2007) The presence of BRAF point mutation in adult papillary thyroid carcinomas from atomic bomb survivors correlates with radiation dose. Mol Carcinog 46(3): 242-248.

Talerko N (2005) Reconstruction of (131)I radioactive contamination in Ukraine caused by the Chernobyl accident using atmospheric transport modelling. J Environ Radioact 84(3): 343-362.

Tronko M, Mabuchi K, Bogdanova T, Hatch M, Likhtarev I, Bouville A, Oliynik V, Mcconnell R, Shpak V, Zablotska L, Tereshchenko V, Brenner A, Zamotayeva G (2012) Thyroid cancer in Ukraine after the Chernobyl accident (in the framework of the Ukraine-US Thyroid Project). J Radiol Prot 32(1): N65-N69.
Tronko MD, Howe GR, Bogdanova TI, Bouville AC, Epstein OV, Brill AB, Likhtarev IA, Fink DJ, Markov VV, Greenebaum E, Olijnyk VA, Masnyk IJ, Shpak VM, Mcconnell RJ, Tereshchenko VP, Robbins J, Zvinchuk OV, Zablotska LB, Hatch M, Luckyanov NK, Ron E, Thomas TL, Voilleque PG, Beebe GW (2006) A cohort study of thyroid cancer and other thyroid diseases after the chornobyl accident: thyroid cancer in Ukraine detected during first screening. J Natl Cancer Inst 98(13): 897-903.

Tuttle RM, Vaisman F, Tronko MD (2011) Clinical presentation and clinical outcomes in Chernobyl-related paediatric thyroid cancers: what do we know now? What can we expect in the future? Clin Oncol (R Coll Radiol) 23(4): 268-275.

UNSCEAR (2010) United Nations Scientific Committee on the Effects of Atomic Radiation: Sources and Effects of Ionizing Radiation. United Nations: New York, NY, USA.

UNSCEAR (2013) United Nations Scientific Committee on the Effects of Atomic Radiation: Sources, Effects and Risks of Ionizing Radiation. United Nations: New York, NY, USA.

Williams D (2008) Radiation carcinogenesis: lessons from Chernobyl. Oncogene 27(Suppl 2): S9-S18.

Williams ED (2000) Guest Editorial: Two Proposals Regarding the Terminology of Thyroid Tumors. Int J Surg Pathol 8(3): 181-183.

Williams ED, Abrosimov A, Bogdanova T, Demidchik EP, Ito M, Livolsi V, Lushnikov E, Rosai J, Sidorov Y, Tronko MD, Tsyb AF, Vowler SL, Thomas GA (2004) Thyroid carcinoma after Chernobyl latent period, morphology and aggressiveness. Br J Cancer 90(11): 2219-2224.

Zablotska LB, Nadyrov EA, Rozhko AV, Gong Z, Polyanskaya ON, Mcconnell RJ, O'kane P, Brenner AV, Little MP, Ostroumova E, Bouville A, Drozdovitch V, Minenko V, Demidchik Y, Nerovnya A, Yauseyenka V, Savasteeva I, Nikonovich S, Mabuchi K, Hatch M (2015) Analysis of thyroid malignant pathologic findings identified during 3 rounds of screening (1997-2008) of a cohort of children and adolescents from belarus exposed to radioiodines after the Chernobyl accident. Cancer 121(3): 457-466.

This work is published under the standard license to publish agreement. After 12 months the work will become freely available and the license terms will switch to a Creative Commons AttributionNonCommercial-Share Alike 4.0 Unported License.

Supplementary Information accompanies this paper on British Journal of Cancer website (http://www.nature.com/bjc) 